\title{
INTERPRETASI POTENSI EKOWISATA DUSUN DAROK KECAMATAN BONTI KABUPATEN SANGGAU KALIMANTAN BARAT
}

\author{
(Interpretation of Potentials of Economic Darok, Darok Kecamatan Bonti Distric, Sanggau \\ West Kalimantan)
}

\author{
Resti Islamiati, Siti Masitoh Kartikawati, Tri Widiastuti \\ Fakultas Kehutanan Universitas Tanjungpura. Jalan Daya Nasional Pontianak 78124 \\ Email : restiislamiati@yahoo.com
}

\begin{abstract}
Darok hamlet is located in the bonti sub district of sanggau district. Has many tributaries such as the Hisi, river the Himua and Tangis, the Darok and the Bonti river. Darok hamlet has good natural forest. Has the status of protected forest areas Mount Budu, Iron Mountain, there are protected plants Amorphophallus titanium dan Rafflesia tuan mudaee young master one of West Kalimantan endemic. There are animals like tringgiling, jungle cats, and proboscis mongkeys which are still widely around the river. Darok village is also still thick with 'Gawai' traditions. The purpose of ths study was to record the potential of ecotourism and develop interpretations of the ecotourism potential of the village of Darok. The method used is exploration and ascending coordinates and direct interviews with hamlet heads, custom temenggung and local communities. The results of explroration there are 28 attractions that can support the interpretation of ecotourism potential, namely 18 physical potentials, 3 potential rare and endemic plants, 7 culture potentials. The results of the exploration were develoved into two tour package pathways, namely the protected forest path package and social culture this package was made based on field research. The protected forest package is on the heavy side, the settlement is $3 \mathrm{~km}$ away, there are potential waterfalls cascades, cascade amorphophallus titanium and others. While the social culture route in the north is $1 \mathrm{~km}$ away there is potential for tembawang forest, rice fields, traditional houses, and others
\end{abstract}

Keywords: Ecotourism, Interpretation, Pathway Interpretation.

\section{PENDAHULUAN}

Ekowisata yaitu sebagai bentuk perjalanan wisata ke area alami yang dilakukan dengan tujuan mengkonservasi lingkungan serta melestarikan tanpa merusak potensipotensi yang ada pada kawasan ekowisata tersebut, serta melestarikan kehidupan dan meningkatkan kesejahteraan penduduk setempat serta meningkatkan taraf perekonomian yang ada pada masyarakat sekitar (Suriani, 2011).
Interpretasi sebagai suatu cara untuk menjembatani antara sumberdaya yang ada dengan seseorang atau kelompok yang ingin mengetahui lebih tentang sumberdaya itu. Interpretasi adalah pelayanan kepada pengunjung yang datang ke hutan, tempat-tempat yang dilindungi dan tempat-tempat rekreasi sejenis lainnya (Muntasib, 2014).

Dusun Darok terletak di Kecamatan Bonti Kabupaten Sanggau. Dusun ini memiliki banyak anak sungai kecil seperi sungai Hisi, sungai Himua dan Tangis, sungai Darok dan sungai Bonti. 
Dilihat dari kondisi hutan dusun Darok memiliki hutan alam yang masih baik. Wilayah dusun Darok memiliki status kawasan hutan lindung yaitu Hutan Lindung Gunung Budu Gunung Besi dan banyaknya terdapat tanaman hutan seperti Durian, Tengakawang, Meranti terdapat juga tanaman yang dilindungi yaitu Amorphopalus titanum dan Rafflesia tuan mudaee salah satu jenis endemik Kalimantan Barat, terdapat juga satwa seperti tringgiling, kucing hutan, serta bekantan yang masih banyak disekitaran tepi sungai dusun Darok serta masih adanya sosial budaya masyarakat yang masih dilestarikan hingga saat ini. Mayoritas masyarakat dusun Darok ini adalah etnis dayak Daro yang hidup berdampingan dengan masyarakat dayak lainnya seperti dayak Ribun, Tingin, Mayau, Sami, Selayang. Dusun Darok dikelilingi oleh beberapa bukit (biasanya masyarakat Darok menyebutkan Gunung). Berbagai potensi yang dimiliki dusun Darok perlu dikembangkan sebagai Desa Wisata dengan menggunakan konsep ekowisata. Sehingga penting dilakukan penelitian Interpretasi Potensi Ekowisata. Agar dapat memberikan manfaat dan juga mengelola kawasan hutan secara lestari dan berwawasan lingkungan pada masa yang akan datang.

Penelitian ini bertujuan untuk mendata potensi ekowisata dan menyusun Interpretasi Potensi Ekowisata dusun Darok Kecamatan Bonti Kabupaten Sanggau.

\section{METODE PENELITIAN}

Penelitian ini dilaksanakan di dusun Darok Kecamatan Bonti Kabupaten Sanggau Kalimantan Barat selama \pm 1 bulan mulai tanggal 26 September 2019 - 26 Oktober 2019. Objek Penelitian yang diamati di dusun Darok meliputi masyarakat dan ekosistem yang berada didalam dusun tersebut. Data yang dikumpulkan yaitu data primer dan sekunder, data primer berupa data interpretasi potensi ekowisata yang terdapat di dusun Darok seperti data potensi sumber daya alam dan budaya data ini diambil berdasarkan penitikan koordinat dilapangan, meliputi:

a) Fisik, seperti hutan, kebun, ladang, persawahan, sungai, bukit, gunung dan lainnya.

b) Biologis, meliputi flora dan fauna seperti tumbuhan berguna, keunikan, langka, dilindungi, dan memiliki nilai budaya.

c) Sosial budaya masyarakat meliputi tradisi, ritual adat, kesenian, makanan khas, tempat bersejarah

Data sekunder data yang diambil dari monografi dusun Darok, mengenai kondisi umum lokasi penelitian, sejarah dusun, serta data penunjang di dusun Darok yang. Pengambilan data ini dilakukan untuk menentukan objek dengan menggunakan GPS, serta melakukan studi pustaka dan wawancara.

Data yang dikumpulkan kemudian diolah dengan cara membuat tabulasi, berisikan berbagai data yang sudah diberi kode sesuai dengan analisis yang dibutuhkan. Dengan jenis data dan 
tujuan penggunaannya. Analisis data disajikan dalam bentuk deskriptif kualitatif. Analisis dilakukan terhadap hasil Interpretasi Potensi Ekowisata dusun Darok selanjutnya dilakukan pembahasan sehingga diperoleh kesimpulan jawaban dari subjek penelitian.

\section{HASIL DAN PEMBAHASAN}

Potensi Ekowisata Dusun Darok Kecamatan Bonti Kabupaten Sanggau

Berdasarkan eksplorasi dan wawancara langsung kepada tokoh masyarakat yaitu, Kepala Dusun, Temenggung Adat, dan Masyarakat lokal mengenai potensi ekowisata di dusun Darok. Terdapat 28 objek wisata yang bisa mendukung interpretasi potensi ekowisata. Jumlah total potensi fisik yang didapat sebanyak 18 objek wisata, serta 3 potensi tumbuhan langka, dilindungi, dan endemik, yang terakhir sisanya 7 potensi budaya.

\section{Interpretasi Potensi Fisik Dusun Darok}

Dusun Darok dikelilingi oleh Hutan Lindung menurut SK. 733/ Menhut- II 2014 Tanggal 2 September 2014. Hal ini dikarenakan kawasan hutan yang ada didusun Darok harus dilindungi sesuai fungsi hutan lindung, yaitu agar fungsi ekologisnya terutama yang menyangkut tata air dan kesuburan tanah supaya tetap dapat berjalan dan dinikmati oleh masyarakat sekitar. Potensi fisik yang ada di dusun Darok sangat menarik untuk dilakukan kegiatan interpretasi. Potensi fisik ini yaitu seperti Air Terjun Tingkas, hutan tembawang, kebun karet dan sahang, ladang, sawah, sungai Hisi, sungai Darok, sungai Himua dan Tangis, Sungai Bonti, riam Layua, riam Batu Ampar, riam Domin, riam Kepala Anjing, Gunung Budu Gunung Besi, bendungan air darok, Batu Lebur dan Batu Guno.

a. Air Terjun Tingkas

Air Terjun Tingkas berada disebelah Barat dusun Darok. Air terjun ini berjarak $\pm 5 \mathrm{~km}$ dari pemukiman masyarakat Darok, terletak pada titik koordinat $\mathrm{N} 00^{\circ} 32.976^{\prime} \mathrm{E} 110^{\circ} 34.001^{\prime}$. Air terjun ini dapat ditempuh dengan menggunakan sepeda motor dengan waktu \pm 25 menit dari permukiman setelah itu dilanjutkan dengan berjalan kaki menelusuri hutan.

b. Hutan Tembawang

Menuju kehutan tembawang ini, bisa ditempuh dalam waktu \pm 10 menit dari pemukiman dengan jarak tempuh 1 km. Masyarakat dusun Darok memiliki 2 hutan tembawang yaitu tembawang Socju yang berada disebelah Utara dari pemukiman dan tembawang Juah yang berada di sebelah barat dari dusun Darok, terletak pada titik koordinat $\mathrm{N}$ $00^{\circ} 33.012^{\prime} \mathrm{E} 110^{\circ} 34.295$.

c. Kebun

Sebagian besar masyarakat dusun Darok memiliki kebun karet dan kebun sahang, kebun karet dan sahang berada disebelah Utara dari pemukiman masyarakat, Untuk menuju kebun ini, bisa ditempuh dalam waktu \pm 20 menit dari pemukiman dengan jarak tempuh \pm 3-4 km. Kebun sahang terletak pada titik

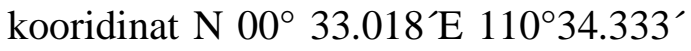
dan kebun karet terletak pada titik koordinat $\mathrm{N} 00^{\circ} 33.201^{\prime} \mathrm{E} .110^{\circ} 35.017$. 
Hampir semua warga setiap harinya pergi ke kebun untuk menoreh getah karet dan ke kebun sahang untuk memetik sahang. Hasil dari kebun karet yang dikelola oleh masyarakat akan dikumpul terlebih dahulu sampai waktunya cukup untuk dijual.

d. Ladang

Ladang pada masyarakat Darok berada disebelah Utara dari pemukiman terletak pada titik koordinat $\mathrm{N} 00^{\circ}$ 33.444’ E $110^{\circ} 35.318^{\prime}$ dan ada juga terdapat disebelah Barat jalur sebelum menuju air terjun tingkas. Untuk menuju keladang ini bisa ditempuh dalam waktu \pm 10 menit dengan jarak tempuh $\pm 1 \mathrm{~km}$ dari pemukiman.

e. Sawah

Masyarakat Darok selain sebagai petani karet dan petani sahang hampir sebagian memiliki sawah rata- rata luas \pm 2 ha. Sawah masyarakat Darok ini berada disebelah Utara dari pemukiman, terletak pada titik koordinat $\mathrm{N} 00^{\circ}$ $33.862^{\prime} \mathrm{E} 110^{\circ} 35.318^{\prime}$. Untuk menuju kesawah ini bisa ditempuh dalam waktu \pm 10 menit dengan jarak tempuh $\pm 1 \mathrm{~km}$ dari pemukiman. Masyarakat dusun Darok melakukan panen padi selama 3 kali panen dalam satu tahun. Dari hasil sawah yang mereka dapatkan mereka gunakan untuk untuk mencukupi kebutuhan sehari-hari seperti pangan, akan tetapi hasil dari sawah mereka tidak mereka jual kepasar dikarenakan hampir seluruh masyarakat memiliki sawah tersebut.

\section{f. Sungai}

Dilihat dari hasil yang dilakukan pada saat observasi lapangan, dusun Darok memiliki banyak anak sungai seperti sungai Hisi yang berada disebelah Barat pemukiman, sungai Himua dan sungai Tangis yang berada disebelah Barat dari pemukiman, sungai Darok yang menjadi sungai utama berada disebelah Utara dari pemukiman dan sungai Bonti yang menjadi jalur transportasi berada disebelah Barat pemukiman. Sungai tersebut memiliki keunikan dan cerita tersendiri sehingga menarik untuk dikembangkan menjadi potensi ekowisata.

g. Riam

Menurut Tanaya (2014) riam merupakan aliran air deras seperti air terjun, tetapi tidak memiliki ketinggian melainkan hanya mencapai ketinggian \pm $1 \mathrm{~m}$. Bagian dari sungai dimana dasar sungai memiliki kemiringan yang relatif curam, menyebabkan peningkatan kecepatan air menjadi lebih dangkal dengan beberapa batu terbuka di atas permukaan aliran. Riam yang terdapat di dusun Darok ini umumnya memiliki riam yang bebatuan seperti riam Layua yang berada disebelah Barat pemukiman, riam Batu Ampar berada dekat dengan pemukiman yaitu sebelah Utara, riam Domin berada disebelah Utara pemukiman dan terletak paling ujung setelah riam Batu Ampar, riam Kepala Anjing berada tepat dibawah air terjun tingkas yaitu sebelah Barat dari pemukiman. Masing- masing dari riam ini memiliki keunikan tersendiri sehingga dapat menjad potensi ekowisata yang baik untuk dikembangkan. 


\section{h. Gunung Budu Gunung Besi}

Dusun Darok dikelilingi oleh hutan lindung yaitu Gunung Budu Gunung Besi, Hutan lindung ini telah ditetapkan menurut SK.733/Menhut-II 2014 Tanggal 2 September 2014. Gunung ini berada disebelah Barat dari pemukiman terletak pada titik koordinat $\mathrm{N} 00^{\circ}$ $33.007^{\prime}$ E $110^{\circ} 34.277^{\prime}$. Untuk menuju gunung ini bisa ditempuh dalam waktu \pm 30 menit dengan jarak tempuh $\pm 4 \mathrm{~km}$ dari pemukiman. Penamaan gunung ini dikarenakan dengan kawasan hutan yang ada di dusun Darok harus dilindungi sesuai fungsi Hutan Lindung yaitu agar fungsi ekologisnya terutama yang menyangkut tata air dan kesuburan tanah supaya tetap dapat berjalan dan dinikmati manfaatnya oleh masyarakat sekitar.

i. Bendungan Air Darok

Bendungan air yang masih digunakan sebagai sumber air bersih masyarakat darok terletak tidak jauh dari pemukiman warga, bendungan ini berada disebelah Utara dari pemukiman dan terletak pada titik koordinat $\mathrm{N} 00^{\circ}$ 34.080' E $110^{\circ} 34.846^{\prime}$. Bendungan merupakan bendungan permanen berbentuk kolam segi empat yang disalurkan untuk kebutuhan air masyarakat. Untuk menuju bendungan ini bisa ditempuh dalam waktu \pm 8 menit dengan jarak tempuh $\pm 800 \mathrm{~m}$ dari pemukiman.

j. Batu Lebur dan Batu Guno

Masyarakat dusun Darok merupakan masyarakat yang masih mempercayai dengan mitos dan legenda, salah satunya adalah mitos batu lebur yang berada ditengah hutan sebelah
Barat dari pemukiman dusun Darok, terletak pada titik koordinat $\mathrm{N} 00^{\circ}$ 33.407' E $110^{\circ} 35.367^{\prime}$. Untuk menuju batu ini bisa ditempuh dalam waktu \pm 18 menit dengan jarak tempuh $\pm 2-3 \mathrm{~km}$ dari pemukiman.

\section{Intrepretasi Potensi Tumbuhan Dusun Darok}

Berdasarkan ekspolrasi dilapangan serta wawancara langsung bersama masyarakat lokal terdapat \pm 30 jenis, dan terdapat jenis pohon yang dominan adalah karet (Hevea brasilliensis), sahang (Piper nigrum), bambu (Dendrocalmulus asper), dan ada beberapa jenis pohon dari family dipterocarpaceae seperti bengkirai (Shorea leaviolia), damar (Shorea replosula), damar putih (Shorea perugenia).

a. Potensi Tumbuhan Pada Kebun

Masyarakat dusun Darok memiliki masing-masing kebun sebagai mata pencaharian mereka, yaitu kebun sahang dan kebun karet. Letak kebun ini tidak jauh dari permukiman warga, hampir semua warga setiap harinya pergi ke kebun untuk menoreh getah karet dan ke kebun sahang untuk memetik sahang liar juga dapat disebut kebun asalkan berada didekat permukiman warga (Sleman, 2009).

b. Potensi Tumbuhan Pada Ladang

Ladang biasanya ditanami tanaman musiman dan penggunaannya hanya semusim atau dua musim, kemudian akan ditinggalkan bila sudah tidak subur lagi (berpindah-pindah). Kemungkinan lahan ini beberapa tahun kemudian akan 
dikerjakan kembali jika sudah subur (IBS Yogi, 2018). Tanaman yang ditanami diladang seperti ubi atau singkong, kacang panjang, kentang, kedelai, kacang hijau, perenggi dan lainnya.

c. Potensi Tumbuhan Pada Bambu

Masyarakat Darok mengenal bambu dengan sebutan buluh, banyak terdapat jenis bambu lokal seperti bambu Munti, bambu Puso, bambu buru, bambu Po'yat, bambu Burunai, bambu Tinyl. Pemanfataan bambu ini digunakan untuk kehidupan sehari-hari yang dibuat anyaman berupa tikar, jarai (homba), tali jarai (hirok), tampi (tampik). Selain itu masyarakat juga memanfaatkan bambu untuk pembuatan jembatan, lanting (rakit), kandang ternak dan peralatan lainnya.

d. Potensi Tumbuhan Pada Tanaman Rempah dan Obat- obatan

Daerah dataran tinggi seperti pegunungan yang ada di dusun Darok ini banyak ditemukan jenis tanaman tanaman obat yang masih digunakan masyarakat setempat sebagai tanaman rempah pengganti masak dan masih digunakan oleh dukun- dukun sebagai obat-obatan seperti:

\section{Daun Sengkubak}

Daun ini tumbuh ditengah hutan berada sebelah Barat dari dusun Darok terletak pada titik koordinat $\mathrm{N} 00^{\circ}$ 34.007’ E $110^{\circ} 34.261^{\prime}$ jarak tumbuhan ini dengan dusun Darok agak sedikit sulit ditempuh dikarenakan yang berjarak lumayan jauh \pm 2 - $3 \mathrm{~km}$ atau tepatnya tumbuh dibawah riam layua. Tanaman ini digunakan masyarakat sebagai pengganti rempah dapur yaitu micin untuk menambah rasa yang ada ada pada masyarakat. Daun ini tumbuh bebas liar yang jauh dari hutan. Foto yang dilampirkan adalah daun sengkubak yang sudah diolah oleh masyarakat.

\section{Pasak Bumi}

Daun pasak bumi tumbuh di hutan dan berada disebelah Barat dusun Darok Daun ini terletak pada titik koordinat $\mathrm{N}$ $00^{\circ} 33.007^{\prime}$ E $110^{\circ} 34.161^{\prime}$. Apabila ingin melihat tumbuhan pasak bumi ini dapat ditempuh dengan waktu \pm 27 menit dengan jarak tempuh $\pm 4 \mathrm{~km}$ dari dari pemukiman. Masyarakat menggunakan daun pasak bumi untuk obat seperti diabetes, kencing manis, dan ada juga masyarakat yang menggunakan nya untuk stamina kekuatan tubuh.

e. Potensi Tumbuhan Yang Dilindungi

Tumbuhan dilindungi ditetapkan berdasarkan beberapa faktor. Faktor tersebut antara lain menurunnya populasi liar, sebaran terbatas (endemik), berkurangnya habitat, pemanfaatan yang tidak berkelanjutan. Oleh karena itu masyarakat melestarikan jenis tumbuhan yang dilindungi dengan cara tidak mengambilnya dari alam jika kita menemukannya (Kusmana, 2015). Dusun Darok memiliki tumbuhan yang dilindungi, sehingga di dusun Darok ini memiliki nilai potensi ekowisata yang baik untuk dikembangan. Tumbuhan yang hidup di dusun Darok yaitu bunga bangkai raksasa Amorpopallus titanum dan tumbuhan endemik kalimantan Rafllesia tuan mudaee.

\section{Amorphopallus titanum}


Amorphopallus titanumm adalah tanaman berbunga dengan tidak bercabang Apabila bunga ini mekar dan besar bunga ini dapat mencapai diameter hingga $1 \mathrm{~m}$. Tunas-tunas biasanya muncul ditempat sulur tumbuh ditanah. Bunga ini kami temukan pada saat ingin menuju lokasi air terjun Tingkas bunga ini berada disebelah Barat dusun Darok dan terletak pada titik koordinat $\mathrm{N} 00^{\circ}$ $33.007^{\prime}$ E $110^{\circ} 34.254^{\prime}$. Untuk menuju ke lokasi tanaman ini dapat ditempuh dengan waktu \pm 25 menit dari pemukiman dengan jarak tempuh \pm 4 $\mathrm{km}$.

\section{Rafllesia tuan mudaee}

Bunga endemik Kalimantan ini berada disebelah Barat dusun Darok dan terletak pada titik koordinat $\mathrm{N} 00^{\circ}$ 33.016 ' E $110^{\circ} 34.279^{\prime}$. Untuk menuju ke lokasi ini dapat ditempuh dengan waktu \pm 20 menit dengan jarak tempuh \pm 3-4 km dari pemukiman. Tanaman ini berada dalam kawasan hutan lindung. Masyarakat setempat bunga ini disebut bunga dewa karena bentuknya yang besar dan mengeluarkan bau yang menyengat

f. Potensi Tumbuhan yang Bernilai Mistis

Berbagai tumbuhan yang tumbuh di Indonesia memiliki bunga- bunga yang memikat mata. Tidak hanya itu, harum bau dari bunga tertentu pun membuat relaks siapapun yang menciumnya. Tapi ada berbagai jenis tumbuhan-tumbuhan yang bernilai mistis seperti tumbuhan yang ada di dusun Darok ini yaitu bulu perindu dan bambu munti, yang masih menjadi kepercayaan masyarakat setempat.

\section{Interpretasi Potensi Hewan Dusun Darok}

Potensi fauna yang terdapat di dusun Darok banyak ada yang bermanfaat sebagai obat penawar racun, dan ada juga yang memiliki nilai mistis. Dari berbagai potensi yang diketahui oleh masyarakat tersebut dusun Darok terdapat banyak habitat dari berbagai jenis satwa liar seperti Bekantan (Nasalis larvatus), Owa-owa (Hylobates muelleri), Trenggiling (Manis javanica), Babi hutan ( Sus scorofa), Kucing hutan (Prionailurus planiceps) dan masih banyak mamalia lainnya. Selain itu ditemukan berbagai jenis burung, ular.

Berdasarkan hasil wawancara pada masyarakat mengenai potensi fauna yang diperoleh. Ada terdapat jenis-jenis fauna yang terkait dengan mistis aja juga fauna yang dipercaya oleh masyarakat setempat mempunyai kekuatan gaib, jenis- jenis fauna yang dimanfaatkan oleh masyarakat dan pemanfaatannya, fauna yang dijumpai berada disebelah Barat dusun Darok yaitu Trenggiling (Manis javanica) terletak pada titik koordinat N $00^{\circ} 33.007^{\prime} \mathrm{E} 110^{\circ} 34.211^{\prime}$. Potensi fauna yang ada di dusun Darok sangatlah banyak dan masih tergolong terjaga serta dilindungi. Walaupun masyarakat Darok masih menerapkan sistem berburu, tetapi mereka juga masih tetap menjaga hewan- hewan yang dilindungi ini, tidak diambil dan diburu sembarangan

\section{Interpretasi Potensi Budaya Masyarakat Dusun Darok}


Budaya merupakan salah satu daya tarik yang dapat menarik pengunjung untuk mendatangi lokasi tersebut. Masyarakat dusun Darok masih memegang teguh nilai-nilai budaya nenek moyang tanpa melupakan nya. Mayoritas penduduk masyarakat Darok adalah suku Dayak 'Daro' dan sebagian besar suku melayu. Potensi budaya masyarakat Dayak Daro ini merupakan suatu yang menarik dinikmati pengunjung. Potensi ini dapat dimanfaatkan dalam kegiatan interpretasi sebagaimana dikemukakan oleh Widya, (2019) bahwa kebudayaan merupakan salah satu unsur penting dalam Interpretasi dan dapat dijadikan pilihan potensi untuk Interpretasi

1. Tradisi

Tradisi diartikan sebagai sesuatu yang telah diinginkan untuk sejak lama dan menjadi bagian dari kehidupan suatu kelompok masyarakat. Dalam pengertian tradisi ini, hal yang paling mendasar dari tradisi adalah adanya informasi yang diteruskan dari generasi ke generasi baik tertulis maupun lisan. Masyarakat dusun Darok masih mengenal adanya tradisi- tradisi oleh nenek moyang yang tidak bisa ditinggalkan seperti, Gawai Adat Panen Padi yang dilaksanakan pada tanggal 20 Mei oleh masyarakat Dayak Daro, Gawai Tebas yang dilaksanakan 10 hari setelah Gawai Panen Padi, Berhuma merupakan tradisi menanam padi bekas pembakaran ladang, dan beremah yaitu kegiatan gotong royong.

a. Ritual Adat
Upacara pada umumnya memiliki nilai sakral oleh masyarakat pendukung kebudayaan tersebut. Upacara adat adalah suatu upacara yang secara turun- temurun dilakukan oleh suatu daerah. Dengan demikian setiap daerah memiliki upacara adat sendirisendiri seperti upacara adat perkawinan, kelahiran dan kematian. Ritual adat yang dilakukan oleh masyarakat dusun Darok sangat beranekaragam sehingga itu membuat ciri khas dari dusun tersebut sangat terlihat. Ritual adat tersebut seperti Pomang Umpan Pedagi, Rumah Adat.

b. Kesenian

Beragamnya kesenian yang dimiliki oleh masyarakat dusun Darok membuat dusun tersebut memiliki banyak seni mulai dari tarian adat seperti, tari adat penyambutan, tari Belian, tari Ngayau atau tari Kepala.

c. Makanan khas

Makanan khas adalah makanan yang menjadi karakter suatu daerah tersebut yang dapat mencerminkan ciri khas suatu daerah, dari cita rasanya dan tidak. Pada setiap daerah memiliki makanan khas yang berbeda, salah satunya masyarakat Darok yang memiliki makanan khas seperti, lemang, lemang bujang, ayam masak bambu, pekasam ikan/ podak

d. Tempat keramat

Tempat keramat merupakan tempat yang dianggap mulia seperti pemakaman masyarakat. Tempat keramat ini menjadi tempat yang dikunjungi apabila ingin berziarah. Tidak sedikit juga ada masyarakat yang pergi ketempat keramat 
untuk meminta keberuntungan dengan memuja roh-roh halus yang dianggap ada. Masyarakat dusun Darok memiliki tempat keramat seperti, Bambu Munti dan Kuburan.

e. Cerita rakyat

Cerita rakyat adalah cerita yang berasal dari masyarakat dan berkembang dalam masyarakat pada masa lampau yang menjadi ciri khas setiap daerah yang memiliki kultur budaya yang beraneka ragam, mencakup kekayaan budaya dan sejarah yang dimiliki masing-masing daerah tersebut. Ada banyak cerita rakyat dusun Darok yang menarik dan masih menjadi cerita hingga saat ini dan diketahui oleh masyarakat seperti, Batu Guno, Tengkorak Ngayau, Batu Lebur, Burung Kocu.

\section{Paket Interpretasi Potensi Ekowisata Dusun Darok}

Berdasarkan hasil eksplorasi daya tarik wisata di dusun darok bisa dikembangkan menjadi jalur paket wisata yaitu paket jalur Hutan Lindung dan paket jalur Sosial Budaya. Paket ini dibuat berdasarkan penitikan yang diambil dilapangan. Dengan adanya paket ini akan lebih mudah membuat pengunjung yang datang ke dusun Darok untuk mengetahui jalur mana saja yang memiliki potensi menarik yang diamati. Paket ini terbagi atas 2 jalur dilampirkan melalui lampiran peta jalur Hutan Lindung dan peta jalur Sosial Budaya.

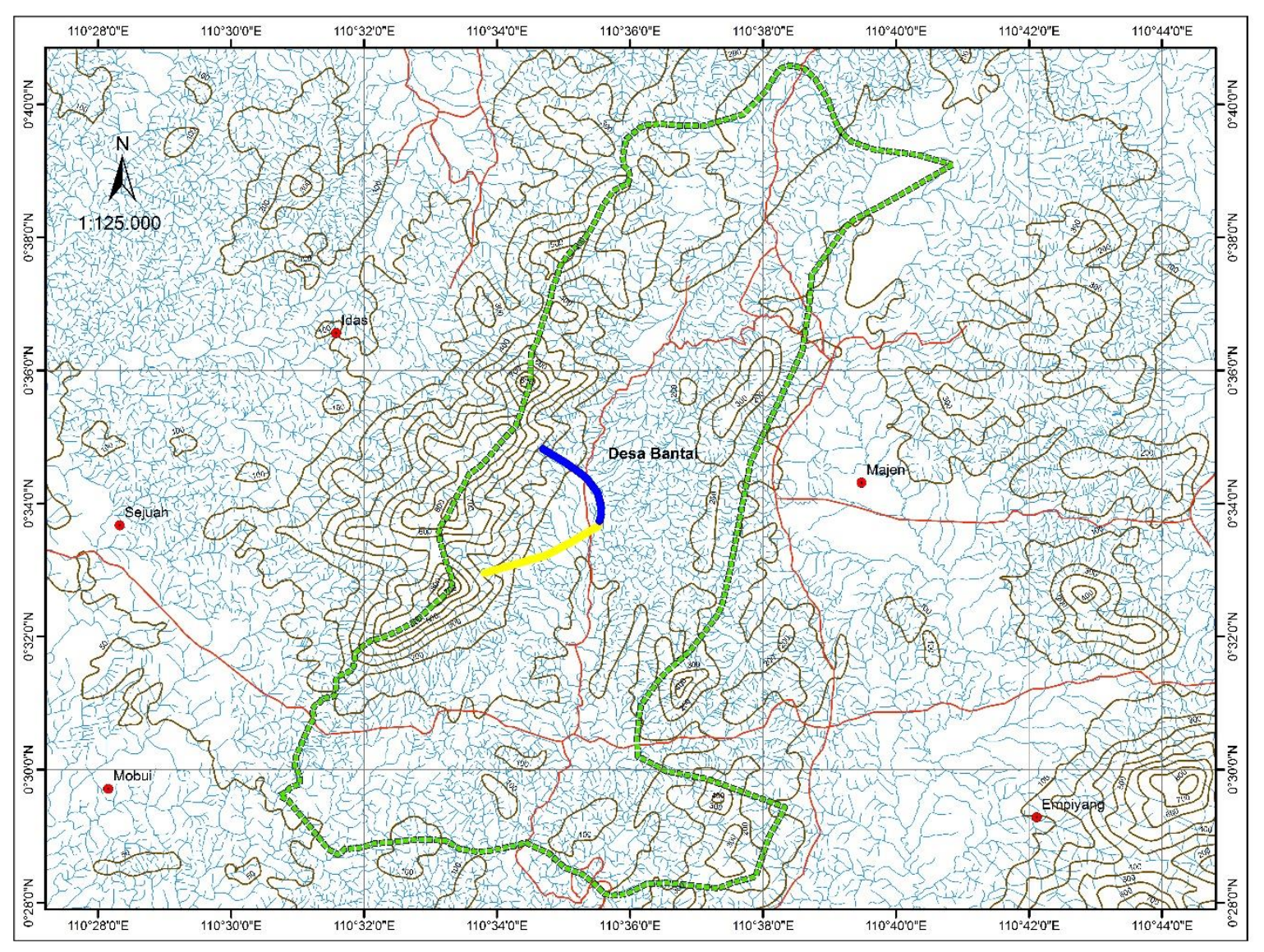


Figure 1. Jalur Interpretasi Potensi Ekowisata dusun Darok (Ecotourism Interpretation Pathway Map in Darok Village)

Keterangan : _ Jalur Hutan Lindung (Protected forets Path) Jalur Sosial Budaya (Social Cultural Path)

Interpretasi Paket Jalur Hutan Lindung

Perjalanan menuju jalur Hutan Lindung berada disebelah Barat dari pemukiman, jalur ini dapat ditempuh menggunakan sepeda motor ataupun berjalan kaki, akan tetapi jika berjalan kaki akan lebih jauh dikarenakan akan memutari dusun Darok \pm 3 jam. sedangkan jika menggunakan sepeda motor dapat ditempuh dalam waktu \pm 40 menit dengan jarak $6 \mathrm{~km}$ dari pemukiman. Paket jalur hutan lindung ini memang banyak potensipotensi menarik seperti air terjun tingkas, riam Layua, riam kepala anjing, Amorphophallus titanium, Rafflesia tuan mudae sehingga nantinya diharapkan dengan paket ini dapat memudahkan serta meminimalisir biaya yang dikeluarkan untuk menikmati pesona indah dusun Darok.

\section{Interpretasi Paket Jalur Sosial Budaya}

Jalur sosial budaya ini merupakan jalur kedua yang ada pada dusun Darok, Jalur ini berada disebelah Utara pemukiman dusun Darok, Jalur ini berada dekat dengan perkampungan masyarakat. Jalur yang berjarak $\pm 4 \mathrm{~km}$ dari dusun. Untuk menuju jalur ini bisa ditempuh dalam waktu \pm 25 menit. Potensi wisata yang ada pada jalur sosial budaya yaitu, sarana pendidikan, rumah adat, hutan tembawang, sungai Darok, sawah, riam Batu Ampar, riam Domin dan ladang masyarakat. Paket jalur sosial budaya banyak terdapat juga potensi budaya yang menarik, mulai dari keanekaragaman dan hasil hutan yang bermacam- macam seperti HHBK dan buah dari hasil hutan tembawang.

\section{KESIMPULAN}

Berdasarkan eksplorasi dan wawancara langsung kepada tokoh masyarakat yaitu, Kepala Dusun, Temenggung Adat, dan Masyarakat lokal mengenai potensi ekowisata di dusun Darok. Terdapat 28 objek yang bisa mendukung interpretasi potensi ekowisata. Jumlah total potensi fisik yang didapat sebanyak 18 objek wisata, serta 3 potensi tumbuhan langka, dilindungi, dan endemik, yang terakhir sisanya 7 potensi budaya.Potensi fisik meliputi Air Terjun Tingkas, hutan tembawang, kebun karet dan sahang, ladang, sawah, sungai Hisi, sungai Darok, sungai Himua dan Tangis, sungai Bonti, riam Layua, riam Batu Ampar, riam Domin, riam Kepala Anjing, Gunung Budu Gunung Besi, bendungan air Darok, Batu Lebur dan Batu Guno. Sedangkan jumlah potensi tumbuhan sebanyak 3 objek wisata yaitu Bunga Bangkai Raksasa Amorphophallus titanum, Bunga endemik Kalimantan Rafflesia tuan mudaee dan Pasak Bumi Eurycoma longifolia. Pada titik fauna terdapat 1 titik potensi yaitu Trenggiling (Manis javanica). Sisanya dilakukan penitikan pada potensi budaya sebanyak 7 potensi budaya.

Berdasarkan penelitian terdapat potensi ekowisata yang dibagi dalam 2 jalur dengan tema jalur Hutan Lindung dan jalur Sosial Budaya. Jalur Hutan Lindung 
berjarak $\pm 6 \mathrm{~km}$ dari dusun Darok dan memiliki waktu tempuh \pm 40 menit. Paket jalur Hutan Lindung terdapat potensi ekowisata seperti, sungai Hisi yaitu sungai yang dikelilingi oleh pohon- pohon enau, sungai Himua dan sungai Tangis, kebun sahang dan kebun karet, hutan tembawang, Batu Lebur dan Batu Guno, pasak bumi, riam Layua, Amorphophallus titanum, Rafflesia tuan mudaee, bambu munti, bambu Puso, riam Kepala Anjing dan destinasi terakhir yaitu Air Terjun Tingkas.

Jalur yang kedua yaitu jalur Sosial Budaya. Jalur ini berada disebelah utara pemukiman dusun Darok, Jalur ini berada dekat dengan perkampungan masyarakat. Jalur ini berjarak $\pm 4 \mathrm{~km}$ dari dusun dengan waktu tempuh \pm 25 menit. Potensi wisata yang ada pada jalur sosial budaya ini yaitu, sarana pendidikan, rumah adat, hutan tembawang, sungai Darok, sawah, riam Batu Ampar, riam Domin dan ladang masyarakat.

\section{SARAN}

1. Perlu adanya peran serta dukungan pemerintah setempat dalam upaya pengembangan wisata dusun Darok ini sehingga nantinya bisa dikembangkan menjadi desa wisata berbasis ekowisata

2. Jalur Interpretasi yang telah direncanakan perlu dievaluasi dalam kurun waktu tertentu agar nantinya jalur tersebut masih tetap bisa digunakan untuk menuju objek lokasi wisata

3. Perlu dibuat interpretasi dengan adanya interpreter baik dari orang setempat sehingga nantinya mengingat pengunjung yang masih banyak ingin berkunjung ke Dusun tersebut lebih memudahkan mereka.

\section{DAFTAR PUSTAKA}

IBS Yogi. 2018. Padi Gunung pada Masyarakat Dayak Sebuah Budaya Bercocok Tanam Penutur Austraindonesia (Melalui Pendekatan Eutnarkeologi). Forum Arkeologi. 31 (1) : 45-56.

Kusmana. 2015. Potensi Tumbuhan yang Dilindungi dan Memiliki Nilai. Jurnal Hutan Lestari 3 (7) : 12-23.

Muntasib, E. K. S. H. 2003. Interpretasi Wisata Alam. Laboratorium Rekreasi Alam Departemen Konservasi Sumberdaya Hutan Fakultas Kehutanan Institut Pertanian Bogor. 112

Pradityo T, Santoso N, Zuhud E. 2016. Etnobotani di Kebun Tembawang Suku Dayak Iban, Desa Sungai Mawang Kalimantan Barat. Jurnal Media Konservasi. 21 (2) : 23- 29.

Suriani NR, Razak MN. 2011. Pemetaan Potensi Ekowisata di Taman Nasional Baluran. Jurnal Pariwisata 24 (3) : 215-260.

Tanaya, Dahiya R. Rudiarto. 2014. Potensi Ekowisata Berbasis Masyarakat Di Kawasan Rawa Pening Kabupaten Semarang. Jurnal Teknik PWK. 3 (3) :71-81.

Widya W, Meizar R, Devi RK.2019. Perencanaan Program Interpretasi untuk Mendukung Kegiatan Ekowisata di Citamiang Bogor.Jurnal Tujuan dan Daya Tarik Wisata 5(1);11-24. 